\title{
Design of an Online Curriculum Promoting Transformative Learning in Post Professional Doctoral Students
}

\author{
Ingrid Provident Ed.D, OTR/L, FAOTA, Joyce Salls OTD, OTR/L, Cathy Dolhi OTD, OTR/L, FAOTA \\ Jodi Schreiber OTD, OTR/L, Amy Mattila MS. OTR/L, Emily Eckel OTD, OTR/L
}

Chatham University in Pittsburgh PA

\begin{abstract}
Written reflections of 113 occupational therapy clinical doctoral students who graduated from an online program between 2007 and 2013 were analyzed for themes which reflected transformative learning and characteristics of curricular design which promoted transformative learning. Qualitative analyses of written reflections were performed. Several themes emerged which are presented using the framework of Person/Learner, Environment/Learning Context, and Occupation/Engagement in Learning Activities. Strategies such as active learning; assignments that directly apply to students' work settings; implementation of a cohort model; and use of reflection, dialog, and project implementation appear to be effective in facilitating transformative learning in an online clinical doctoral program.
\end{abstract}

\section{Introduction}

Allied health professionals who are working in professions such as nursing, physical or occupational therapy have many choices in today's educational environment when considering options for advanced degrees. For example, if one chooses to enter a traditional Doctor of Philosophy program (i.e. face to face coursework, comprehensive exams, writing/defending a research dissertation, etc.), the educational experience will be significantly different than enrollment in a clinical doctorate delivered in an online format. In an online clinical doctoral program, communication between instructors and students 
is mediated through technology rather than traditional classroom interactions. Dialogue in online educational environments may be conducted asynchronously-i.e., postings on a course website can be read at a different time by each party—or in synchronous formats—i.e., auditory and/or written words are heard or read in real time. As a result, student learning in clinical and online doctoral programs will be affected by the structure of online curricula and instructors' abilities to guide student learning (Simons, Baron, Knicely, \& Richardson, 2001).

For students pursuing a post-professional degree online, there are both benefits and drawbacks. Hollis and Madill (2006) described the perceived advantages of online learning as increased choice and flexibility, less disruption to personal lives, and decreased travel time. In a study of nursing students in a hybrid post-professional program, Smyth, Houghton, Cooney, and Casey (2012) found online learning - in addition to its advantages - posed a number of challenges. These included a sense of isolation and lack of community, a lack of feedback, technical problems, and a sense of invasiveness.

Online university courses and programs are increasingly available. Over six million students took an online university level course in 2010. This is a 10\% increase from the previous year (Statistic Brain Research Institute, 2013). Availability of online education and enrollment is expected to continue to increase. Given the growth of online educational opportunities it is important to understand what educational practices effectively enable doctoral students to develop and learn. Additionally, if transformative learning is a desired outcome, understanding the theory and its relationship to the structure of a curriculum to foster the perspective shift and preparation of doctoral students is imperative. The study of transformative learning in the online environment is a focus for contemporary research. Specifically, the aim of this paper is to further the understanding of how the curricular structure of an online post professional occupational therapy doctoral program contributed to the transformative learning experiences of students enrolled in the program.

\section{Literature Review}

Transformative learning theory focuses on an adult learner's ability to reflect and make new meaning of experiences and environments (Allen, 2007). The theory has evolved over the past three decades as others (Benson, Hewitt, Heagney, Devos, \& Crosling, 2010; Boyd, 2009; Matthew-Maich, Ploeg, Jack, \& Dobbins, 2010; Taylor, 2007) have expanded upon the seminal work of Mezirow (1997). Guided by this theory, the student often experiences change as the result of a multiple step process frequently characterized by a disorienting dilemma, followed by the use of active learning, and reflection. The dilemma can serve as a catalyst for learners to examine their assumptions and beliefs through engagement in self-reflection and discourse with others related to changing their view. According to transformative learning theory, this process results in the reorganization of perspective with action to promote change (Santalucia \& Johnson, 2010). The product is a learner who emerges with skills to effect broader change.

The scientific literature includes outcome studies of doctoral students' transformative learning experiences. Boyer, Maher, and Kirkman (2006) identified evidence of transformative learning in an online graduate course by using systematic content analysis of students' written reflections. Their findings suggested that phases of transformative learning were evident in student comments and that fundamental changes in ideas, beliefs, habits, or assumptions occurred for approximately one-fourth of students in relation to course workload, competence with technology, social role priorities, and collaborative learning. The role of the instructor was identified as vital to facilitation of transformative learning. 
According to Henderson (2010) in a synthesis of research related to transformative learning in the online environment, critical reflection, discourse, trusting relationships, and support are the main components in fostering student progression towards transformative learning. The learner experiencing a dilemma is challenged to question previously held assumptions and to consider alternatives through exploratory prompts and critical reflection (Matthew-Maich, et al., 2010; Mezirow, 2000). The role of the online educator using critical reflection and facilitating discourse is to foster the development of the learner by creating opportunity for the inquiry process, thus enabling the student to move beyond technical procedures. This critical reflection provides an opportunity for learners to reflect on experiences and assumptions resulting in a shift in thinking, or transformation (Mezirow, 1997). It is postulated that reflective writing can facilitate introspection and thoughtful consideration of new ideas and can be a strategy to promote reflective practice (Langley \& Brown, 2010; Schön, 1987). Other authors consider discourse with peers related to self-reflection on beliefs, feelings, and values an essential component of critical self-reflection and promotion of transformative learning (Meyers, 2008; Olaniran, 2005).

Trusting relationships and establishing support have been cited as important elements in facilitating transformative learning processes in online environments. In a survey of 59 doctoral graduates, Stevens-Long, et al. (2012) reported transformative learning outcomes that surpassed intellectual growth. Participants identified key experiences perceived to be linked to these outcomes as “...interpersonal relationships (faculty-student and student-student) characterized by community support, collegial relations with faculty, inclusion of diverse people and perspectives, and bonding with fellow students: curricular content and structure that lead to a transformation in perspective and worldview” (p. 191).

While not cited in the literature related to online learning environments, Cranton and Carusetta, (2004), state:

In the final phases of transformation, the learner tries out new roles in an attempt to test and validate new frames of reference. The learner can only achieve this role-playing by engaging in critical discourse with others and then reflecting on that discourse. Once a new role has been tried and validated, learners can then reintegrate the new learning and way of knowing into their previous understanding, reconciling the old and new. (p. 24)

The literature related to online learning seems to be lacking with regard to the final step of the transformative process, trying new roles and taking action. Specifically how can an online program foster the ability of students to take action and try out new roles while receiving the critical reflection, discourse, trusting relationships, and support from their peers and instructors?

In an effort to understand the effects of an online program's curricular sequence and the ability of the instructors to promote transformative learning, the following questions were used to guide the research:

Question 1: What is the evidence of transformative learning in the written reflections of occupational therapy students upon completion of a post-professional online doctoral program?

Question 2: How does the design of an online doctoral program facilitate a student's progression through the stages of transformative learning? 


\section{Educational Context of the OTD Program}

In 1994, the post-professional clinical doctorate in occupational therapy (OTD) emerged as an option for credentialed occupational therapists to advance their understanding of the profession. The doctoral program at this university is an online post-professional OTD which is designed as a cohort model for professionals working in the field. New cohorts begin each fall and spring term, with students assigned to their cohort upon admission to the program. Each cohort is maximized at 15 students. In circumstances where more than 15 students are accepted for a start term, two cohorts are created with equal numbers of students. When two cohorts exist in a term, consideration is given to dividing the students to maximize diversity in terms of practice settings, years of experience, and writing proficiency as demonstrated in the application essay. A cohort model was chosen in an effort to create a community of learners from geographically and professionally diverse areas. The cohort group of students remains together throughout the program, which includes ten courses over a 16-month time frame. Each course in the curriculum is linked and courses are delivered asynchronously through the Moodle web-based platform. The majority of the OTD students are employed full time and work in a variety of settings including academia, community, and hospital based facilities. Each course in the OTD curriculum is designed to foster active learning by including assignments that can be applied directly to each student's area of professional interest/practice. All courses include ongoing discussion forums facilitated by instructors and multiple opportunities for students to engage in reflective writing activities and peer review processes. Students are enrolled in two or three courses per semester with two visits to campus required over the entire program-one visit occurs during a leadership course, and the second visit occurs at the conclusion of students' capstone projects. The visits are intended to facilitate a sense of community among the cohort members as well as to provide a connection to the university.

The OTD program was purposely designed to facilitate a change in the learner to enable each student to translate the best available evidence to occupational therapy practice. As part of the doctoral requirements, OTD students are required to complete a capstone project, which includes development, implementation, and evaluation of an evidence-based project. This process occurs over four academic semesters and culminates in an on campus visit where students present their capstone projects via both oral and poster presentation.

During the first evidence-based practice course which occurs in the first semester of the program, students propose a focused question that addresses a dilemma in their workplace and each student performs an independent preliminary search of the evidence. In the next semester, students systematically gather literature that provides possible resolutions to their dilemma and complete assignments that begin to allow them to demonstrate skill in understanding the scientific literature. While completing these assignments, students engage in facilitated discussions related to the new skill set of obtaining, understanding, and translating the research to resolve their workplace issue. Students write a synthesis of this body of evidence and engage in a formal peer review and feedback process with students in their cohort. Thus, critical reflection and discourse are inherent in the program design through both the writing assignments and interaction with peers and instructors. The curricular intention is to promote habit formation in critical reflection, and the practice of sending the student back to the published literature and guiding him or her to articulate newly acquired knowledge and shifting perspective.

The culmination of this first part of the transformative process results in the development of the action plan for an individualized capstone project to be carried out in the student's workplace. The specific objective of this early portion of the online program is the development of professional habits and behavior patterns within a culture of support and trust. In the remainder of the online program, student capstone projects are implemented in their unique work context. Students continue to be supported by their peers in the cohort as well as the instructor who continues to require online participation through discussion prompts. This active discussion and reflection is designed to have students share their 
experiences in trying out their new roles in their worksites. As the outcomes of their individual projects are shared online with their trusted peers, students have the opportunity to integrate this new learning into their previous ways of understanding their role in their own workplace. This process culminates with students formally sharing both the process and results of their implemented project during the second oncampus visit.

\section{Method}

\section{Participants}

One hundred thirteen occupational therapy doctoral students graduated from the post-professional OTD program from April 2007 to April 2013 and were included in this study. This university's Institutional Review Board (IRB) reviewed and approved the research proposal for this project. Student identifiers were removed from students' reflections and replaced with a code number to ensure confidentiality. Retrospective review of the data was considered ethical in protection of human subjects and approval was granted through exempt level review.

\section{Data Collection}

As part of the capstone project, students wrote reflections about their experiences in the program. These reflections were published in their capstone manuscripts. Their reflective writing was the last section of their capstone project and was written in fulfillment of an open ended writing prompt requesting students write an epilogue of their journey. As a way of having students critically reflect, a portion of the last chapter of the written capstone project is titled "Final Reflections" in which students reflect on their experience in the program. Review of these written reflections formed the basis for this current study exploring transformative learning in this online doctoral program.

Members of the program faculty familiar with transformative learning theory noticed that some students described experiences suggestive of disorienting dilemmas, critical self-reflection, altered perspectives, and plans for acting differently in the world and their workplace. This recognition led members of the faculty to methodically analyze the reflections for themes related to transformative learning.

\section{Data Analysis}

The framework of the Person-Environment-Occupation (PEO) Model (Law et al., 1996) was used as the first level of systematically categorizing the written reflections considering the elements that impacted the students' performance. This occupational therapy model asserts an individual's performance emerges as the result of the "transaction that occurs among the person, environment, and occupation in which the person engages" (p. 17). In doing so, the framework of the model also offers concrete parameters for defining each of the three components (person, environment, and occupation).

The person in the PEO model is considered to be a composite of physical, cognitive, and affective components that enable the individual to do, think, and feel. The person in this study is the OTD student (learner) who can be described as being a "dynamic, motivated and an ever-developing being, constantly interacting with the environment” (Law et al., 1996, p. 17).

The PEO model characterizes the environment, as "the context within which the occupational performance of the person takes place” (Law et al., 1996, p. 17). In this study, the environment is the online learning context. The environment (learning context) includes consideration of cultural, institutional, physical, and social elements that have the potential to impact one's performance. 
Occupations in the PEO model "include activities and tasks done to complete a purpose" (Law et al., 1996, p. 17). Amidst a variety of formal definitions in the occupational therapy literature, occupations have been defined as "....activities that bring meaning to the daily lives of individuals...and enable them to participate in society” (American Occupational Therapy Association, 2011). The occupation of interest in this study is the student's active participation and learning in the OTD program.

The theoretical thinking behind using the PEO model for categorizing the student reflections is that when the three components of the model are working in synchrony, the individual is able to successfully engage in desired occupations within the contextual confines associated with the occupation. This engagement is referred to as occupational performance. In this study, the online OTD program, a deliberately structured learning process, is intended to influence the way the student thinks about and engages in new ways of providing evidence-based occupational therapy services at the student's worksite. The PEO model further asserts if one or more of the three components (Person, Environment or Occupation) negatively impacts the "fit" with the others in some way, occupational performance may be impacted. If the three components are working together with good "fit" the authors assert that transformative learning may result.

Student reflections were analyzed and categorized into reflections about the Person/Learner, Environment/Learning Context, and the Occupation/Student Engagement with the Curriculum/Active Learning. These three distinct areas allowed for the thematic analysis of student reflections as pertaining to: a) statements which reflected transformative learning experiences through the unique perspective changes in person (Learner), b) comments about the online curriculum (Learning Context), and c) what the students did as a result of the design of the online curriculum (Active Learning).

Of the 113 reflections which ranged in length from one to four pages, 79 (70\%) revealed reflective writings that were independently judged by five faculty members to include statements of transformative learning. These student reflections contained unsolicited evidence, which revealed a shift in thoughts and/or feelings demonstrating the student's transformative learning as a result of the educational process of the online doctoral program. These statements included newly revised understandings of self and/or relationships with others as well as a plan to apply new perspectives to their professional activities. The 34 student reflections (30\%) that did not contain evidence of transformative learning were excluded from further analysis. These student reflections were primarily descriptions of the education process and lacked personal connection. For example, they concretely outlined the sequence of their projects and acknowledged participants and instructors.

Codes were collapsed into themes during a secondary qualitative analysis which kept the PEO distinctions intact while integrating the steps of the transformative learning process and highlighting the curriculum strategies which facilitated student change. Illustrative statements within the Person, Environment, and Occupation were independently re-read and analyzed by the authors resulting in the themes presented in the results section. The purpose of this stage of analysis was to ensure all themes related to transformative learning in the students' reflections emerged. Statements suggestive of transformative learning were compared and contrasted to clarify emerging patterns and then entered into Atlas software (ATLAS.ti Qualitative Data Analysis, 2013).

The codes were defined as part of the data analysis and organized into themes. These themes are presented in the results section. The final codes and their definitions which resulted during data analyses are included in Tables 1, 2, and 3. 
Table 1 Person/Learner Related Codes

\begin{tabular}{|c|c|c|}
\hline Code & & Definition \\
\hline $\begin{array}{l}\text { Early } \\
\text { Positive }\end{array}$ & Feelings & $\begin{array}{l}\text { statements that indicate positive emotions at the beginning of the program prior to } \\
\text { implementation of project, energized, intellectually engaged, the Ah ha! moment }\end{array}$ \\
\hline $\begin{array}{l}\text { Late } \\
\text { Positive }\end{array}$ & Feelings & $\begin{array}{l}\text { statements that indicate positive emotions occurring during or after implementation } \\
\text { of project (energized, intellectually engaged, the Ah ha ! moment) related to the } \\
\text { OTD program }\end{array}$ \\
\hline $\begin{array}{l}\text { Early } \\
\text { Negative }\end{array}$ & Feelings & $\begin{array}{l}\text { statements that indicate negative emotions at the beginning of the program prior to } \\
\text { implementation of project, frustration, disappointment, anger, hopelessness }\end{array}$ \\
\hline $\begin{array}{l}\text { Late } \\
\text { Negative }\end{array}$ & Feeling & $\begin{array}{l}\text { statements that indicate negative emotions during or after implementation of } \\
\text { project, frustration, disappointment, anger, hopelessness }\end{array}$ \\
\hline Awarenes & s/Beliefs & $\begin{array}{l}\text { statements that reflect awareness of one's own existence, sensations, thoughts, } \\
\text { surroundings, fund of knowledge, spiritual feelings, possession of qualifications to } \\
\text { perform professional role, having suitable or sufficient skill; statements about the } \\
\text { person's worldview, opinion or conviction about their view of the profession, } \\
\text { external to the person - connections to people or concepts }\end{array}$ \\
\hline Individua & Growth & $\begin{array}{l}\text { statements that reflect development of capacity, integrating new knowledge with } \\
\text { prior knowledge, gaining insight, the I learned statements }\end{array}$ \\
\hline Professio & nal Goals & $\begin{array}{l}\text { setting or having plans for one's future as an occupational therapist, professional } \\
\text { agenda }\end{array}$ \\
\hline Personal & Goals & $\begin{array}{l}\text { setting or having plans for one's future as a human being not related to role as an } \\
\text { OT }\end{array}$ \\
\hline \multicolumn{3}{|c|}{$\begin{array}{l}\text { Reliability } \\
\text { To ensure reliability, the authors developed preliminary code definitions and re-examined the statements } \\
\text { against these definitions. Codes were subsequently revised for the purpose of independent sorting into } \\
\text { three categories; person/learner, environment/learning context, and occupation/active learning. Some } \\
\text { codes were combined, and others deleted in this process as faculty met and discussed their independent } \\
\text { results. This discussion continued until the faculty agreed upon the placement of the codes within the } \\
\text { three categories. To establish rigor, graduate students were also trained in the coding process and their } \\
\text { results were compared to those of the faculty. When discrepancies were identified they were discussed } \\
\text { until consensus emerged among the authors. }\end{array}$} \\
\hline
\end{tabular}

Table 2 Environment/Learning Context Related Codes

\begin{tabular}{ll}
\hline Codes & Definition \\
\hline Job Supports & $\begin{array}{l}\text { people or situations at the person's work environment that enhance or assist the } \\
\text { participation of their role as an OTD student }\end{array}$
\end{tabular}

Family people or situations in the person's family (mother, father, spouse sister, brother, etc.) 
Supports that enhance or assist the participation of their role as an OTD student

Faculty people teaching in the OTD Program that enhance or assist the participation of their role Supports as an OTD student

Cohort peers in the OTD Program that enhance or assist the participation of their role as an OTD Supports student

Evidence content of peer reviewed literature that enhance or assist actualization of the Capstone Supports project

Job Barriers people or situations at the person's work environment that detract from the person's ability to participate in their role as an OTD student

Family people or situations in the person's family (mother, father, spouse sister, brother, etc.) Barriers that detract from the participation of their role as an OTD student

Faculty people teaching in the OTD Program that detract from the participation of their role as an Barriers OTD student

Cohort peers in the OTD Program that detract from the participation of their role as an OTD Barriers student

Table 3 Occupation/Active Learning Related Codes

\begin{tabular}{lll}
\hline Codes & Definition \\
\hline $\begin{array}{l}\text { Student Roles \& } \\
\text { Responsibilities }\end{array}$ & $\begin{array}{l}\text { statements indicating performance of assignments the } \\
\text { rights, obligations, and expected behavior patterns } \\
\text { associated with the OTD Program. Statements } \\
\text { indicating performance of tasks required by the } \\
\text { program, factual statements about required } \\
\text { expectations. } \\
\text { Worker Roles }\end{array} \quad \begin{array}{l}\text { statements indicating performance of job duties, the } \\
\text { rights, obligations, and expected behavior patterns } \\
\text { associated with carrying out the role of an occupational } \\
\text { therapist. Statements indicating action of presently } \\
\text { doing, and/or engagement in current actions in work } \\
\text { setting }\end{array}$ \\
\hline
\end{tabular}




\section{Results}

The results of the secondary qualitative analysis of the OTD students' reflections were synthesized to reflect the steps of transformative learning and to address the two research questions that guided this inquiry. Multiple themes emerged and are presented in Table 4.

Table 4 PEO Themes

\begin{tabular}{ll}
\hline PEO & Themes \\
\hline Person/Learner & $\begin{array}{l}\text { Disorienting Dilemma } \\
\text { Critical Reflection }\end{array}$ \\
Environment/Learning Context & $\begin{array}{l}\text { Cohort and Dialog } \\
\text { Experience of Curriculum }\end{array}$ \\
Occupation/Engagement/Active learning & Action on New Meaning Perspectives \\
\hline
\end{tabular}

Person/Learner

\section{Disorienting Dilemma and Critical Reflection}

For working professionals, deciding to take on the role of student, while employed full time, is a significant undertaking. Many students reflected upon why they made the decision to enroll in an online post professional doctoral program and what they hoped to gain. As in the theory of transformative learning, students often make a deliberate choice as a result of some dilemma they are facing. Over 50\% of students identified some struggle they were facing which resulted in their pursuit of a doctoral program. Some students looked to the program to expand their general knowledge base; some noted the specific purpose of becoming an evidence-based practitioner, while others were looking to further their teaching skills. The following quotes illustrate the dilemmas encountered by some of the OTD students:

- "I recognized that I was at a crossroads in my career as an occupational therapist. I needed to expand my knowledge in order to be the best practitioner I could be.”

- "Having recently been downsized from a 20 year OT director role due to corporate cost cutting, I was working to re-engineer my professional occupations and stability. I had combined practitioner, manager, and educator roles throughout my career, and had always hoped to try full-time teaching before I retired.”

- "Before I embarked on this doctoral journey, many people would ask me why I wanted to pursue it. And although I always offered some reasonable answer, I really wasn't altogether sure myself. I enjoyed my job and was successful at it, but something was missing. I needed more.”

While engaged in the classes during the 16-month process of formulating and implementing their individual capstone projects, students reflected on their experiences. Thirty-eight students contributed phrases that illustrated self-awareness and critical reflection such as needing to find balance, direction for their projects, mastery of the process and stress management. It was clear in the written reflections that students experienced several disorienting dilemmas during the process, and that while fully engaged in 
the curriculum they acquired the knowledge and skills to move through the disorienting dilemma into a transformed practitioner as a result of designing and implementing their capstone projects. For example:

- "The early stages of the journey were filled with trepidation and uncertainty - was the topic worthy of intense study; did I have the skills to find and analyze the evidence; would I be able to make correlations between the literature and what I was seeing in my work setting; would I be able to draw conclusions and make recommendations based on the evidence? Over the past year, my knowledge base has expanded and my skills have been honed - both of these factors have led to feelings of increased competence and confidence.”

- "This doctoral journey has been an experience that was full of anxiety and uncertainty at times, but also brought a great deal of excitement with every element of new learning. I was encouraged by the expertise of the OTD faculty at...to go beyond my comfort zone and embrace the challenges that brought me to the finish line of becoming a doctoral level occupational therapist.”

As can be seen in the above passages, students verbalized professional uneasiness or a dilemma that propelled them toward doctoral education. Once they were in the program, students reflected upon continued anxiety and uncertainty that was part of their experience. These comments are reflective of the first step in the transformative learning process.

\section{Environment/Learning Context}

\section{Cohort and Dialog}

Students reflected on the importance of the program's cohort structure, which provided shared experiences and ongoing opportunities to interact with course instructors and other students. All ten courses in the curriculum required students to articulate their developing knowledge and make critical reflections in both written assignments as well as in interactions with peers and instructors. Online discussion often focused on having students synthesize course content and relevant literature with their existing skill set and knowledge base. Fifty-eight students wrote about the importance of the cohort as a source of support during personal triumphs and challenges as evidenced by the following reflections:

- "As a cohort we have supported and encouraged one another."

- "With these early ideas and the nurturing of class discussions, I had an idea that I was passionate about and a topic on which to focus my capstone project."

- "The gifts I have received from the Program, the faculty, and the students in the cohort far outweigh those that I have provided. At no time during this process did I ever feel alone or did I ever feel like I could not reach out to someone in the class.”

These quotes parallel the findings of previous literature (Gilly, 2004; Stevens-Long, Schapiro, \& McClintock, 2012) that found peer and instructor relationships as crucial supports in the transformational process.

\section{Experience of Curriculum}

Another theme that emerged was how students experienced the program's curriculum and how students became more focused and engaged in the learning process as they developed their capstone 
project as oppose to focusing on the outcome of their project. Students wrote about how the structure and sequence of the online program was leading to changes in how they think:

- "Overall, this process of developing a [focused question], researching the studies that provide support to the question, developing an implementation method and writing down all this information in a smooth organized manner has been very rewarding."

- "This process has taught me the importance of looking towards the evidence and using it in making decisions in how I practice occupational therapy in both the school setting and the outpatient arena. To complete this project, I have stepped outside of my traditional method for delivering occupational therapy services and have introduced a novel technique for providing services to students.”

Students transformed into more discerning professionals with an enhanced self-awareness as a result of their engagement with the educational process. Forty-two statements were coded and contributed to this theme. For example, several students self-identified perfectionist qualities and wrote about a transition in the way they thought about these tendencies. They described how they were learning to incorporate self-perceived imperfections into a larger perspective and fund of knowledge.

- 'I am a perfectionist and in my eyes achieving less than perfect would mean failure. I realized if I went through this [educational] journey and aimed for perfection I was genuinely missing the big picture. It was at this moment when I realized I had changed through this journey."

- "Pursuing a doctoral degree was not about getting A's anymore, it was about selfactualization - the process of improving myself as an OT, clinician, student, mentor, colleague, friend, and person. I've always strived for self-improvement and never a moment settled on complacency. This [educational] journey has certainly proved to me that I still have the essential tools to be anything that I want to be and pursue my dreams where my mind will take me.”

Finally students reflected on how they gained new perspectives for addressing the professional dilemma that was the focus of their capstone projects. They described how they acquired needed information and critically incorporated it into their professional plans and activities.

- "This information [acquired during the capstone process] confirmed my interest and emerging passion for reaching out to families. Although it seemed a tremendous task to live up to their expectations and provide them with the assistance and information for which they seemed desperate, I soon realized that the most important thing I was providing the participant with was an opportunity to develop relationships with one another.”

- “A sense of enthusiasm and confidence was reignited. This was what the whole process was supposed to be about. The final semester flew by, and what a different mindset I was in. I could hardly wait to implement my intervention, document results and then share them with anyone who would listen.”

In these quotes students acknowledged a shift in personal perspectives from the time they began the program. These can be seen on both a personal and professional level, with comments related to changes in confidence and self-awareness. Within transformational learning theory, this constitutes the 
middle to latter stages of the process, where students develop revised self-concepts, and a readiness for change.

\section{Occupation/Active Learning}

\section{Action on New Meaning Perspectives}

Many students commented on new directions for their career as a result of being changed by their engagement in the online doctoral learning process. Forty-seven different students' reflections revealed a reorganized and re-energized view of their ability to contribute to the profession as well as a significant gain in their unique skill sets that will allow them to practice differently. For example:

- "This entire process has made me aware of the duty and responsibility that I have as an occupational therapist to physically, socially, morally, and financially support our professional organizations. Knowing what evidence-based practice is has changed the way that I reason in the clinical setting. This process has taught me the importance of seeking definitive answers as I implement occupational therapy interventions to consumers.”

- "This doctoral journey has been a process not solely a destination. It was filled with many struggles and triumphs; experiences that have made this process more fulfilling and rich. I am a different clinician and person as a result of this process. I am different because I have changed and without change there is no growth. I am fortunate for this experience, as it has shaped my professional and personal life in an intangible way. It has changed me in a manner in which cannot be fully explained but must be experienced.”

The above quotes reflect students' increased confidence in their new roles and awareness of positive change. Comments no longer relate to the dilemma of the early stages of the process, but rather indicate a stronger sense of professional identity and a belief in the capacity to use the skills fostered in the program to effect positive change moving forward.

\section{Discussion}

The qualitative analysis of students' written reflections provides valuable evidence related to the transformative learning process of adult learners in an online doctoral program to answer the first research question that guided this study. In reviewing and coding data, the authors gained an acute awareness that inherent to the transformative process, the students experienced an internal struggle/dilemma that prompted them to intentionally engage in the process of pursuing the clinical doctorate. This dilemma varied by student but was commonly associated with a feeling of professional uneasiness such as experiencing a clinical dilemma, being at a career crossroads, working with peers who had acquired a clinical doctorate, and academicians seeking a terminal degree. Students wrote about their experiences of critical self-reflection, acquiring and synthesizing new knowledge, relationships, and interactions triggered by planning and implementing of their capstone project within the program. A theme that emerged from the majority of their statements was the formation of new professional goals and plans based on their transformed perspectives. In summary there is evidence of transformative learning in the written reflections of occupational therapy students upon completion of the online OTD program. These changes described by the OTD students in this study were similar to those described by Stevens-Long, et al. (2012) in that they reflected changes in personal, cognitive, and behavioral development and were focused at the person or learner level. 
The intention of the second study question was to learn how the design of an online doctoral program might facilitate a student's progression through the stages of transformative learning. Student references to growth experiences in the curricular context of the program were classified in the environment/learning context category. Recognition of supports and barriers experienced during the OTD program are consistent with Taylor's (2007) description of the role of context in transformational learning. One of the most frequently noted components of support was students within the cohort. The program was intentionally designed with the expectation that the cohort model would facilitate sharing and comparing of information as well as peer support. Additionally, structuring the program so that the students continue with the support of their peers and instructor while in the implementation phase of the program allowed students to try out their roles in their workplace whereby completing the process of transformative learning. Students did not just intellectually understand the role of becoming an evidencebased practitioner, they remained supported by their peers in the program who challenged them to reflect while they were actively engaged in the process. This important curricular intention of keeping students engaged with the instructor and their peers while implementing their capstone projects supports the final phase of transformative learning shared by Cranton and Carusetta (2004), who propose the critical value in allowing students to try out the new role and integrate the new learning. The transformative learning process was fostered through to the final stage as students continued online engagement with their supportive peers and were challenged to make sense of the new experiences in the facilitated online discussions. Upon completion of the capstone implementation, a final seven week online course where students analyze, reflect on and discuss the outcomes of their capstone projects occurs. This final round of critical reflection and dialog with the cohort enables the students to take ownership of their transformed abilities and action in the world.

In the present study, the investigators noted that the OTD students who experienced a transformation in their learning reported that being part of an interacting cohort had a positive impact on their learning. This positive effect of the cohort model is consistent with transformative learning literature. Eisen (2001) regarded peer dynamics as an important component in transformative learning. Taylor (2007) reported the establishment of relationships and dialog with others as essential to the transformative experience. This study validates and adds to the existing literature the necessary and important element of online curriculum design that supports students through the implementation of doctoral projects. The online support provided to the students through their peers in the cohort particularly during the final phase of the program allows them to experience and reflect on their new way of viewing their transformed perspectives.

Through the process of coding, the authors noted disparity in the frequency of responses illustrating the three aspects of the PEO model. There were significantly more reflective quotes that supported the Person/Learner and Environment/Learning Context categories. The reason for this may be that the prompt for guiding the reflection was open ended and did not direct the student to share reflection on active learning. The reason for this disparity is beyond the scope of this article but may be a topic of interest for those researching student reflection and online learning.

\section{Limitations}

The results of this study are a reflection of the perspectives of a limited number of students from one university's program, and therefore may not be generalizable to other online post-professional programs. Variations in curricular focus and sequence may further restrict the generalizability of this research to other online programs. Additionally, the participants were a highly motivated group of individuals seeking further professional development, which may have accounted for their readiness for transformative learning. 
Furthermore, students were prompted to reflect on their experience in the program within the context of a course assignment and were aware that the primary instructor, possibly influencing their responses, would read their reflections. The reflection prompt did not directly guide the students to reflect on their OTD experience within the lens of transformative learning.

Future studies should include a larger sample size from a variety of online post-professional programs throughout the country. An opportunity to reflect on the experience should be available to students outside of the structure of a class assignment.

\section{Conclusion}

This study supports the notion that transformative learning occurred in a cohort of online doctoral students as evidenced by their written reflections. Students reported individual growth, increased selfawareness, and an acknowledgement of the transition from early feelings of apprehension and self-doubt to increased confidence and comfort with the concept of change. Students also reported the impact of the program on their professional trajectory by describing their commitment to engagement in evidence-based practice and leadership within their professional roles.

The qualitative analysis demonstrated that the multiple steps of the transformative process occurred in the online environment. The majority of students experienced a disorienting dilemma, and had multiple opportunities for critical reflection and discourse throughout the program. The situated capstone portion of the program provided active learning in each student's unique worksite making the personal transformation more evident to the student.

Purposeful curriculum design further contributed to transformative learning of students. The sequence of course delivery guided the students through the transformative process and allowed for individual growth. The findings of this study have implications for both educators and students. Although the study was conducted with post-professional occupational therapy doctoral students, it is anticipated that other professional educational programs and students may benefit from utilizing strategies employed by the authors to promote transformative learning. Strategies such as active learning, assignments that directly apply to and allow students to carry out their new roles in their work settings, implementation of a cohort model, and use of critical reflection have been shown to be effective in facilitating transformative learning in an on-line learning environment. 


\section{References}

Allen, S.J. (2007). Adult learning theory \& leadership development. Leadership Review, 7, 26-36.

American Occupational Therapy Association. (2011). The philosophical base of occupational therapy. American Journal of Occupational Therapy, 65(Suppl.), S65. doi: 10.5014/ajot.2011.65S65.

ATLAS.ti Qualitative Data Analysis. (2013). A world of data in your hand ATLAS.ti. Retrieved from http://www.atlasti.com/index.html

Benson, R., Hewitt, L., Heagney, M., Devos, A., \& Crosling, G. (2010). Diverse pathways in higher education: Using students' stories to identify transformational experiences. Australian Journal of Adult Learning, 50, 26-53.

Boyd, B. (2009). Using a case study to develop the transformational teaching theory. Journal of Leadership Education, 7(3), 50-58.

Boyer, N., Maher, P., \& Kirkman, S. (2006). Transformative learning in online settings: The use of selfdirection, metacognition, and collaborative learning. Journal of Transformative Education, 4(4), 335-360.

Cranton, P., \& Carusetta, E. (2004). Perspectives on authenticity in teaching. Adult Education Quarterly, 55(5). DOI: 10.1177/0741713604268894

Eisen, M.J. (2001). Peer-based professional development viewed through the lens of transformative learning. Holistic Nursing Practice, 16, 30-42.

Gilly, M. (2004). Experiencing transformative education in the "corridors" of a nontraditional doctoral program. Journal of Transformative Education 2(3), 231-241.

Henderson, J. (2010). Transformative learning: Four activities that set the stage. Online Education. Retrieved from http://www.uwex.edu/disted/conference/Resource_library/proceedings/28439_10.pdf

Hollis, V., \& Madill, H. (2006). Online learning: The potential for occupational therapy education. Occupational Therapy International, 13, 61-78.

Law, M., Cooper, B., Strong, S., Stewart, D., Rigby, P., \& Letts, L. (1996). The person-environmentoccupation model: A transactive approach to occupational performance. Canadian Journal of Occupational Therapy, 63(1), 9-23.

Langley, M.A., \& Brown, S.T. (2010). Perceptions of the use of reflective journals in online graduate nursing education. Nursing Education Perspectives, 31(1), 12-17.

Matthew-Maich, N., Ploeg, J., Jack, S., \& Dobbins, M. (2010). Transformative learning and research utilization in nursing practice: A missing link? Worldviews on Evidence- based Nursing, 1, 25-35.

Meyers, S. (2008). Using transformative pedagogy when teaching online. College Teaching, 56, 4, 219224. 
Mezirow, J. (1997). Transformative learning: Theory to practice. New Directions in Adult Continuing Education, 74, 5-12.

Mezirow, J. \& Associates. (2000). Fostering critical reflection in adulthood. San Francisco, CA: JosseyBass.

Olaniran, B. A. (2005). Computer-mediated communication as an instructional learning tool: A course evaluation. In P. Comeaux (Ed.), Assessing Online Learning (pp. 144-158). Massachusetts: Anker Publishing Co.

Santalucia, S., \& Johnson, C.R. (2010). Transformative learning: Facilitating growth and change through fieldwork. OT Practice, 15(19), CE1-CE7.

Schön, D. A. (1987). Educating the reflective practitioner: Toward a new design for teaching and learning in the professions. San Francisco: Jossey-Bass.

Simons, D., Baron J., Knicely, K., \& Richardson, J. (2001). Online learning: Perspectives of students and faculty in two disciplines-occupational therapy and teacher education. Occupational Therapy in Health Care, 14, 21-53.

Smyth, S., Houghton, C., Cooney A., \& Casey D. (2012). Students' experiences of blended learning across a range of postgraduate programmes. Nurse Education Today 32(4), 464-468.Statistic Brain Research Institute (2013), Retrieved from http://www.statisticbrain.com/online-university-statistics/

Stevens-Long, J., Schapiro, S. A., \& McClintock, C. (2012). Passionate scholars: Transformative learning in doctoral education. Adult Education Quarterly, 62, 180-198.

Taylor, E. W. (2007). An update of transformative learning theory: A critical review of the empirical research (1999-2005). International Journal of Lifelong Education, 26, 173-191. 